\title{
Haemato-biochemical studies of Theileria orientalis infection in cross bred dairy cattle
}

\author{
(iD) \\ (iD \\ K. Sudhakar Goud ${ }^{1 *}$, K. Vijayakumar ${ }^{2}$, K. Justin Davis ${ }^{3}$, \\ P.V. Tresamol ${ }^{4}$, Chintu Ravishankar ${ }^{5}$ and K. Devada ${ }^{6}$ \\ Department of Veterinary Epidemiology and Preventive Medicine, \\ College of Veterinary and Animal Sciences, Mannuthy, Thrissur, Kerala, \\ Kerala Veterinary and Animal Sciences University, Pookode, Wayanad, India.
}

Citation: Sudhakar Goud, K., Vijayakumar, K., Justin Davis, K., Tresamol, P.V., Chintu Ravishankar, K. and Devada, K. 2021. Haemato-biochemical studies of Theileria orientalis infection in cross bred dairy cattle. J. Vet. Anim. Sci. 52(1): 42-47. DOI: https://doi.org/10.51966/jvas.2021.52.1.42-47

Received : 13.11.2020

Accepted: 27.11.2020

Published: 01.01.2021

\begin{abstract}
The present work has been carried out to study the haemato-biochemical profiles of cattle infected with oriental theileriosis. Theileriosis was diagnosed in 30 cross bred cattle by blood smear examination and confirmed by PCR. Whole blood samples were collected from positive animals and were subjected to estimation of haemato-biochemical parameters. Haematological analysis revealed significant decrease in total erythrocyte count (TEC), haemoglobin, volume of packed red cells (VPRC) and granulocyte count, significant increase in total leucocyte count (TLC), lymphocyte count, monocyte count and granulocyte count in T. orientalis infected animals. Non-significant changes were noticed in mean corpuscular volume (MCV), mean corpuscular haemoglobin $(\mathrm{MCH})$ and mean corpuscular haemoglobin concentration (MCHC). Biochemical analysis revealed significant decrease in albumin concentration and significant increase in blood urea nitrogen level in T. orientalis infected animals. The knowledge on alterations in haemato-biochemical profiles of affected animals will help to assess the severity of infection and to make a tentative diagnosis of the condition.
\end{abstract}

Key words: Anaemia, Cattle, Theileriosis

Theileria are protozoan parasites that belong to phylum Apicomplexa and infect both domestic and wild animals. Seven different Theileria spp. are known to infect cattle among them Theileria parva (causative agent of East coast fever) and T. annulata (responsible for

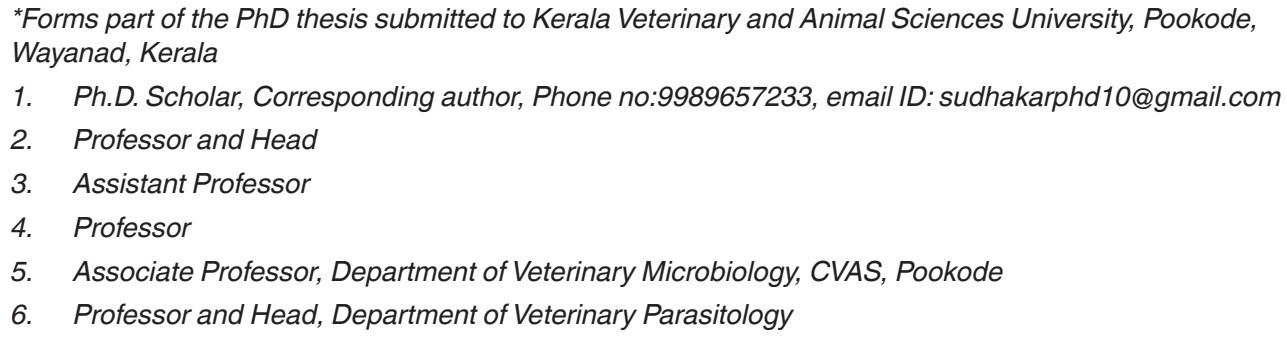

Copyright: () 2021 Sudhakar Goud et al. This is an open access article distributed under the terms of the Creative Commons Attribution 4.0 International License (http://creativecommons.org/licenses/by/4.0/), which permits unrestricted use, distribution, and reproduction in any medium, provided the original author and source are credited. 
Tropical theileriosis) are considered as most pathogenic species due to their ability to transform host lymphocytes. For many years Theileria orientalis, causative agent of oriental theileriosis was considered as benign parasite and caused mild anaemia in infected animals (Kamau et al., 2011). Recently outbreaks of oriental theileriosis were reported from various parts of the world leading to significant production losses, due to high morbidity and death in severe cases (Ota et al., 2009; Aparna et al., 2011, McFadden et al., 2011; Perera et al., 2014; Kim et al., 2017). Theileria orientalis exerts its main effects during piroplasm stage by causing destruction of erythrocytes leading to anaemia in infected animals. Major clinical signs associated with these organisms include fever, inappetence, lethargy, pale mucous membrane, decreased milk production and abortions in pregnant animals (Eamens et al., 2013). The exact pathogenesis of anaemia resulting from $T$. orientalis infection was not clearly understood.

The aim of the present study is to determine the alterations in haematological and biochemical parameters in T. orientalis infected cross bred cattle.

\section{Materials and methods}

Cross bred dairy cattle presented with clinical signs suggestive of theileriosis such as inappetance, lethargy, pale mucous membrane, fever and decreased milk production were included in the study. The infected animals were presented to local veterinary hospitals for treatment.

The animals were screened for theileriosis by microscopic examination of Giemsa stained blood smears. The positive cases were confirmed by species specific PCR as per Tanaka et al. (1993) with slight modification. Thirty animals which were positive for T. orientalis were selected for further study. Six millilitres of blood was collected aseptically from jugular vein from infected animals and control group and $2 \mathrm{ml}$ was transferred to EDTAcoated plastic vials and $4 \mathrm{ml}$ was added into the clot activator vials. The coagulated blood samples were centrifuged at $4000 \mathrm{rpm}$ for 15 min and supernatant (serum) was collected for biochemical estimations.

\section{Haemato-biochemical analysis}

The whole blood samples were analysed for haematological parameters including total erythrocyte count, haemoglobin, volume of packed red cells, mean corpuscular volume (MCV), mean corpuscular haemoglobin $(\mathrm{MCH})$, mean corpuscular haemoglobin concentration (MCHC) , thrombocyte count, total leukocyte count (TLC) and differential leukocyte count by automatic haematological analyser (Orphee Mythic Vet 18). The serum total protein, albumin, aspartate aminotransferase (AST), creatinine and blood urea nitrogen (BUN) were estimated by semi auto analyser (Erba Chem 5 plus V2, India) using commercial kits (Erba Mannheim, India).

\section{Statistical analysis}

The IBM-SPSS software version 24 was used to analyse the data. The differences of mean values of haematological and biochemical parameters were compared by independent sample t-test.

\section{Results and Discussion}

Examination of Giemsa stained blood smear revealed presence of Theileria piroplasms in all the 30 cattle selected for the study. The piroplasm appeared as rod shaped with trailing cytoplasm (Fig. 1).

The DNA extracted from all the infected cattle was subjected to species specific PCR for molecular identification. The species specific PCR with MPSP-F and MPSP-R primer pair yielded $875 \mathrm{bp}$ specific for $T$. orientalis.

\section{Haematological findings}

The haematological values of T. orientalis infected animals and control group were shown in Table 1. Theileria orientalis infected animals had significantly decreased TEC, haemoglobin and VPRC compared to control group. These findings were in agreement with Sivakumar et al. (2017). The decrease in TEC, haemoglobin and VPRC values 
Table 1. Haematological parameters in control group and T. orientalis infected cattle

\begin{tabular}{|c|c|c|c|}
\hline Haematological parameter & $\begin{array}{l}\text { Control group } \\
\qquad(n=6)\end{array}$ & $\begin{array}{l}\text { T. orientalis infected } \\
\text { cattle }(n=30)\end{array}$ & $p$-value \\
\hline Total Erythrocyte count (x106/ $\mu \mathrm{L})$ & $8.22 \pm 0.64$ & $4.06 \pm 0.19$ & $0.00^{* *}$ \\
\hline Haemoglobin (g/dl) & $10.85 \pm 1.13$ & $6.15 \pm 0.26$ & $0.00^{* *}$ \\
\hline VPRC (per cent) & $35.88 \pm 3.99$ & $19.30 \pm 0.82$ & $0.00^{* *}$ \\
\hline $\operatorname{MCV}(f l)$ & $43.88 \pm 3.39$ & $48.63 \pm 1.39$ & $0.17^{\text {ns }}$ \\
\hline $\mathrm{MCH}(\mathrm{pg})$ & $13.22 \pm 0.92$ & $15.48 \pm 0.53$ & $0.07^{\mathrm{ns}}$ \\
\hline MCHC (per cent) & $30.33 \pm 0.51$ & $31.98 \pm 0.68$ & $0.06^{\text {ns }}$ \\
\hline Platelet count $\left(\times 10^{3} / \mu \mathrm{L}\right)$ & $280.17 \pm 42.63$ & $237.67 \pm 25.54$ & $0.47^{\mathrm{ns}}$ \\
\hline Total leucocyte count $\left(\times 10^{3} / \mu \mathrm{L}\right)$ & $9.93 \pm 0.98$ & $14.41 \pm 1.28$ & $0.01^{\star *}$ \\
\hline Lymphocytes (x103/ $\mu \mathrm{L})$ & $2.95 \pm .54$ & $10.00 \pm 1.21$ & $0.01^{* *}$ \\
\hline Monocytes $\left(x 10^{3} / \mu \mathrm{L}\right)$ & $0.82 \pm 0.87$ & $0.53 \pm 0.04$ & $0.001^{\star \star}$ \\
\hline Granulocytes (x103/ $\mu \mathrm{L})$ & $6.17 \pm 0.14$ & $3.89 \pm 0.42$ & $0.05^{\star}$ \\
\hline
\end{tabular}

** Highly significant $(p<0.01),{ }^{*}$ significant at $(p<0.05)$ and ${ }^{\text {ns: }}$ Non-Significant

Table 2. Comparison of biochemical parameters between control animals and T. orientalis infected cattle

\begin{tabular}{|l|c|c|c|}
\hline \multicolumn{1}{|c|}{ Biochemical parameter } & $\begin{array}{c}\text { Control animals } \\
(\mathbf{n = 6})\end{array}$ & $\begin{array}{c}\text { T. orientalis infected } \\
\text { cattle }(\mathbf{n = 3 0 )}\end{array}$ & p-value \\
\hline Total Proteins (g/dL) & $7.91 \pm 0.34$ & $7.25 \pm 0.29$ & $0.33^{\mathrm{ns}}$ \\
\hline Albumin (g/dL) & $3.19 \pm 0.32$ & $2.19 \pm 0.08$ & $0.00^{\text {** }}$ \\
\hline Globulin (g/dL) & $4.72 \pm 0.45$ & $5.05 \pm 0.25$ & $0.59^{\mathrm{ns}}$ \\
\hline Albumin: globulin ratio & $0.73 \pm 0.13$ & $0.46 \pm 0.02$ & $0.09^{\mathrm{ns}}$ \\
\hline Aspartate aminotransferase (U/L) & $62.23 \pm 3.54$ & $60.75 \pm 3.19$ & $0.84^{\mathrm{ns}}$ \\
\hline Creatinine (mg/dL) & $1.38 \pm 0.06$ & $1.24 \pm 0.07$ & $0.37^{\mathrm{ns}}$ \\
\hline Blood urea nitrogen $(\mathrm{mg} / \mathrm{dL})$ & $13.72 \pm 2.48$ & $21.89 \pm 1.46$ & $0.02^{*}$ \\
\hline
\end{tabular}

** Highly significant $(p<0.01),{ }^{*}$ Significant at $(p<0.05)$ and ${ }^{\text {ns: Non-Significant }}$

resulted due to development of anaemia in T. orientalis infected animals. The pathogenesis of anaemia in $T$. orientalis infected animals was not clearly established and it may be multifaceted. Increased osmotic fragility of erythrocytes leading to abnormal morphology (Yagi et al., 1989), reduced survival rate of both infected and uninfected erythrocytes (Yagi et al., 1991) and oxidative damage and lipid peroxidation of erythrocytes (Yagi et al., 2002) were considered to play important role in the development of anaemia in T. orientalis infected animals. Shiono et al. (2003) reported increased methaemoglobin concentration leading to production of free radicles and resulting in oxidative damage to RBC membranes in T. orientalis infected animals.

The infected animals had increase in $\mathrm{MCV}, \mathrm{MCH}$ and $\mathrm{MCHC}$ values compared to control group, but the increase was not statistically significant. Kim et al. (2017) and Jackson (2018) reported significantly increased $\mathrm{MCV}, \mathrm{MCH}$ and $\mathrm{MCHC}$ values in T. orientalis infected animals. This might be due to host specific responses to haemolysis that determine the development of anaemia in infected animals (Sivakumar et al., 2017). No significant difference was observed in the platelet values between infected animals and control group, indicating that thrombocytopaenia was not a feature of $T$. orientalis infection in cattle (Lawrence et al., 2018).

A significant increase in TLC, lymphocyte count and significant decrease in monocyte count and granulocyte count was observed in $T$. orientalis infected animals 


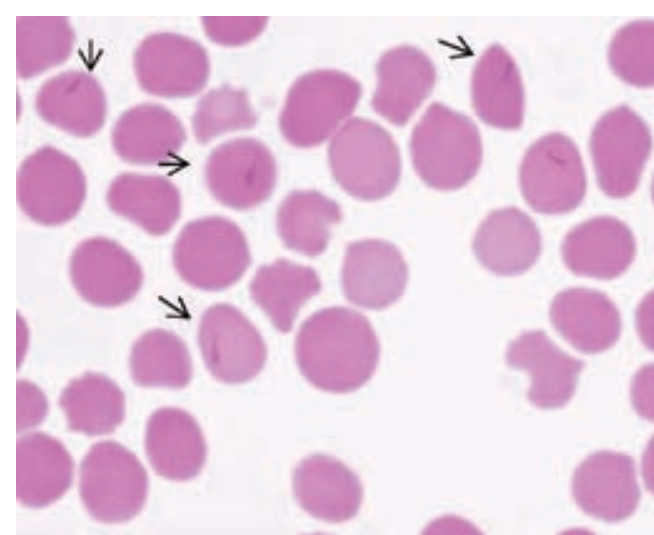

Fig. 1. Giemsa stained blood smear showing rod shaped T. orientalis piroplasm

\section{$\begin{array}{llllllllllll}1 & 2 & 3 & 4 & 5 & 6 & 7 & 8 & 9 & 10 & 11 & 12\end{array}$}

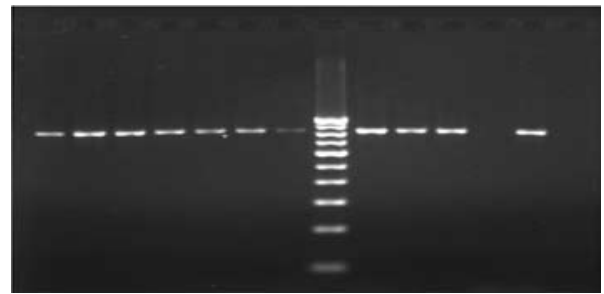

Lane M: 100 bp ladder

Lane 1 to 10 samples positive for T. orientalis Lane 11: Negative control ; Lane 12: Positive control

Fig. 2. Agarose gel electrophoresis of $P C R$ amplified products of $T$. orientalis

compared to control group. Marked luecocytosis was observed in $T$. orientalis infected animals this was in agreement with Kim et al. (2017). Shimizu et al. (1990) reported that $T$. sergenti piroplasms contain an adjuvant substance that activates the bovine lymphoid or myeloid system leading to changes in peripheral lymphocyte and leucocyte count during infection.

The morphological changes observed in erythrocytes of $T$. orientalis infected cattle include anisocytosis, basophilic stippling, poikilocytosis. The haematological changes revealed macrocytic and normochromic anaemia. Macrocytosis, polychromacia and basophilic stippling indicated regenerative response in $T$. orientalis infected animals which was consistent with that of haemolytic diseases.

\section{Biochemical findings}

The mean serum biochemical values of $T$. orientalis infected animals and control group were shown in Table 2. Hypoproteinaemia was observed in $T$. orientalis infected animals but it was not statistically significant when compared with control group. The finding of significant decrease in mean albumin concentration in $T$. orientalis infected animals was in agreement with Stockham et al. (2000). Hypoalbuminaemia might be due to impairment in synthesis, extensive protein degradation and increased albumin excretion due to renal damage, in infected animals. Hypoproteinaemia and hypoalbuminaemia might be due to extravascular accumulation of proteinaceous fluid in body cavities (Stockham et al., 2000).

Theileria orientalis infected animals had increased mean globulins compared to 875bp control group. This might be due to immune response to the $T$. orientalis infection as suggested by lzzo et al. (2010).

In the present study, BUN concentration but not creatinine was significantly increased in $T$. orientalis infected animals. Similar findings were reported in $T$. annulata infected animals by Dede et al. (2014), which they suggested might be due to increased turnover of proteins and renal damage associated with increased catabolism of haemoglobin in infected animals.

There was no significant difference in the mean AST activity, as expected to raise in response to extravascular haemolysis in T. orientalis infected animals, which was in agreement with Lawrence et al., (2018). No significant difference was observed in the mean serum creatinine, total proteins, globulins and aspartate aminotransferase (AST) activity between infected animals and control group.

\section{Ethical approval and consent statement}

Oral consent was taken from the owner of the animals before drawing blood from animals. There is no specific law in India that requires permission from the ethics committee for collecting less than $5 \mathrm{ml}$ of blood and further 
blood samples were collected from the infected animals presented to veterinary hospitals as a part of clinical diagnosis by qualified veterinarians.

\section{Acknowledgement}

The authors are thankful to Kerala Veterinary and Animal Sciences University for providing facilities for carrying out research.

\section{References}

Aparna, M., Ravindran, R., Vimalkumar, M.B., Lakshmanan, B., Rameshkumar, P., Kumar, K.A., Promod, K., Ajithkumar, S., Ravishankar, C., Devada, K. and Subramanian, H. 2011. Molecular characterization of Theileria orientalis causing fatal infection in crossbred adult bovines of South India. Parasitol. Int. 60: 524-529.

Dede, S., Altug, N., Deger, Y., Ozdal, N. and Ceylan, E. 2014. Serum biochemical profile and protein fractions in cattle with Theileriosis. Revue. Med. Vet. 165: 137143.

Eamens, G.J., Gonsalves, J.R., Jenkins, C., Collins, D. and Bailey, G. 2013. Theileria orientalis MPSP types in Australian cattle herds associated with outbreaks of clinical disease and their association with clinical pathology findings. Vet. Parasitol. 191: 209-217.

Izzo, M.M., Poe, I., Horadagoda, N., De Vos, A.J. and House, J.K. 2010. Haemolytic anaemia in cattle in NSW associated with Theileria infections. Aus. Vet. J. 88: 45-51.

Jackson, B. 2018. Clinico-therapeutic studies on bovine theileriosis. M.V.Sc thesis, Kerala Veterinary and Animal Sciences University, Pookode, 123p.

Kamau, J., de Vos, A.J., Playford, M., Salim, B., Kinyanjui, P. and Sugimoto, C. 2011. Emergence of new types of Theileria orientalis in Australian cattle and possible cause of theileriosis outbreaks. Parasit. Vectors 4: 22-31.
Kim, S., Yu, D.H., Chae, J.B., Choi, K.S., Kim H.C., Park, B.K., Chae, J.S. and Park J. 2017. Pathogenic genotype of major piroplasm surface protein associated with anemia in Theileria orientalis infection in cattle. Acta. Vet. Scand. 59: 1-5.

Lawrence, K.E., Forsyth, S.F., Vaatstra, B.L., McFadden, A.M.J., Pulford, D.J., Govindaraju, K. and Pomroy, W.E. 2018. Clinical haematology and biochemistry profiles of cattle naturally infected with Theileria orientalis Ikeda type in New Zealand. N.Z. Vet. J. 66:21-29.

McFadden, A.M.J., Rawdon, T.G., Meyer, J., Makin, J., Morley, C.M., Clough, R.R., Tham, K., Müllner, P. and Geysen, D. 2011. An outbreak of haemolytic anaemia associated with infection of Theileria orientalis in naive cattle. N.Z. Vet. J. 59: 79-85.

Ota, N., Mizuno, D., Kuboki, N., Igarashi, I., Nakamura, Y., Yamashina, H., Hanzaike, T., Fujii, K., Onoe, S., Hata, H. and Kondo, S. 2009. Epidemiological survey of Theileria orientalis infection in grazing cattle in the eastern part of Hokkaido, Japan. J. Vet. Med. Sci. 71: 937-944.

Perera, P.K., Gasser, R.B., Firestone, S.M., Anderson, G.A., Malmo, J., Davis, G., Beggs, D.S. and Jabbar, A. 2014. Oriental theileriosis in dairy cows causes a significant milk production loss. Parasit. Vectors 7: 73-81.

Shimizu, S., Yagi, Y., Nakamura, Y., Shimura, K., Fujisaki, K., Onodera, T., Minami, T. and Ito, S. 1990. Clinico-hematological observation of calves experimentally infected with Theileria sergenti. Nippon Juigaki Zasshi 52: 1337-1339

Shiono, H., Yagi, Y., Chikayama, Y., Miyazaki, S. and Nakamura, I. 2003. Oxidative damage and phosphatidylserine expression of red blood cells in cattle experimentally infected with Theileria sergenti. Parasitol. Res. 89: .228-234. 
Sivakumar, T., Ikehara, Y., Igarashi, I., Inokuma, H. and Yokoyama, N. 2017. Dynamics of erythrocyte indices in relation to anemia development in Theileria orientalisinfected cattle. J. Protozool. Res. 27: 2333.

Stockham, S.L., Kjemtrup, A.M., Conrad, P.A., Schmidt, D.A., Scott, M.A., Robinson, T.W., Tyler, J.W., Johnson, G.C., Carson, C.A. and Cuddihee, P. 2000. Theileriosis in a Missouri beef herd caused by Theileria buffeli: case report, herd investigation, ultrastructure, phylogenetic analysis, and experimental transmission. Vet. Pathol. 37: 11-21.

Tanaka, M., Onoe, S., Matsuba, T., Katayama, S., Yamanaka, M., Yonemichi, H., Hiramatsu, K., Baek, B.K., Sugimoto, C. and Onuma, M. 1993. Detection of Theileria sergenti infection in cattle by polymerase chain reaction amplification of parasite-specific DNA. J. Clin. Microbiol. 31: 2565-2569.

Yagi, Y., Furuuchi, S., Takahashi, H. and Koyama, H. 1989. Abnormality of osmotic fragility and morphological disorder of bovine erythrocytes infected with Theileria sergenti. Jpn. J. Vet. Sci. 51: 389-395.

Yagi, Y., Ito, N. and Kunugiyama, I. 1991. Decrease in erythrocyte survival in Theileria sergenti-infected calves determined by non-radioactive chromium labelling method. J. Vet. Med. Sci. 53: 391-394.

Yagi, Y., Thongnoon, P., Shiono, H. and Chikayama, Y. 2002. Increase in oxidized proteins in Theileria sergenti-infected erythrocyte membrane. J. Vet. Med. Sci. 64: 623-625. 